\title{
Kinerja Model Fisik Konverter Energi Ombak Rangkaian Gear Searah pada Periode Ombak yang Bervariasi
}

\author{
Masjono Muchtar \\ Jurusan Teknik Sipil, Universitas Hasanuddin, Makassar \\ Jl. Perintis Kemerdekaan Km.10, Makassar, 90245, Sulawesi Selatan \\ E-mail: masjono@yahoo.com \\ Salama Manjang \\ Jurusan Teknik Elektro, Universitas Hasanuddin, Makassar \\ Jl. Perintis Kemerdekaan Km.10, Makassar, 90245, Sulawesi Selatan \\ E-mail: salamamanjang@gmail.com \\ Dadang A Suriamiharja \\ Jurusan Fisika, Universitas Hasanuddin, Makassar \\ Jl. Perintis Kemerdekaan Km.10, Makassar, 90245, Sulawesi Selatan \\ E-mail: dahmaduh@gmail.com \\ M. Arsyad Thaha \\ Jurusan Teknik Sipil, Universitas Hasanuddin, Makassar \\ Jl. Perintis Kemerdekaan Km.10, Makassar, 90245, Sulawesi Selatan \\ E-mail: athaha_99@yahoo.com
}

\begin{abstract}
To date there were few research on the effect of non-linearity properties of the ocean waves on the performance of wave energy converter (WEC), which uses a series of unidirectional gear. One such parameter is the variation of wave period. The influence of wave period variations on the performance of physical model of the wave energy converters have been investigated at the Hydraulics Laboratory, Department of Civil Engineering, Hasanuddin University Indonesia. This WEC physical model was fabricated and assembled at Politeknik ATI Makassar Indonesia. The investigation steps consists of physical model development, physical model investigation at wave flume prior to the wave period variation, measuring input output parameters of the physical model under test and empirical model formulation based on observed data analysis. Physical model test carried out on the wave flume at the Hydraulics Laboratory of the Department of Civil Hasanuddin University, at a water depth of $25 \mathrm{~cm}$, wave height between $5-9 \mathrm{~cm}$ and wave period between 1.2 - 2.2 seconds. Investigation result based on flywheel radial speed (RPM) and torque $(\mathrm{Nm})$ indicated that calculated harvested power was inversely proportional with the wave period. The longer the period of the waves, the energy produced is getting smaller. The derived empirical formula was $y=-85.598 x+208.53$ and $R^{2}=0.8881 . Y$ is energy produced (Watt) and $X$ is the wave period (Second). Formulations generated from this study could be used as a reference for future research in dealing with wave period variations on a design one way gear wave energy converter as a source of renewable energy.
\end{abstract}

Keywords: Renewable energy, Wave energy converter, Wave period.

\begin{abstract}
Abstrak
Penelitian mengenai pengaruh non linieritas ombak terhadap wave energy converter (WEC) yang menggunakan rangkaian gear searah belum banyak dilakukan. Salah satu parameter non linieritas tersebut adalah periode dan tinggi ombak yang bervariasi. Pengaruh parameter non linieritas akibat variasi periode ombak terhadap model fisik konverter energi ombak tersebut telah di teliti di Laboratorium Hidrolika
\end{abstract}


Jurusan Sipil Universitas Hasanuddin dan fabrikasi model tersebut dilakukan di Politeknik ATI Makassar. Tahapan penelitian ini meliputi fabrikasi dan assembly model fisik, uji model fisik, mengukur parameter model pada periode ombak yang bervariasi, formulasi model matematis hubungan antar variable. Uji model fisik dilakukan pada wave flume di Laboratorium Hidrolika Jurusan Sipil Universitas Hasanuddin, pada kedalaman air $25 \mathrm{~cm}$, tinggi ombak antara $5-9 \mathrm{~cm}$ dan periode ombak antara 1,2 - 2,2 detik. Hasil pengukuran energi berdasarkan kecepatan putaran (RPM) dan torsi (Nm) poros plywheel yang dihasilkan model fisik konverter ombak menunjukkan bahwa semakin panjang periode ombak maka energi yang dihasilkan semakin kecil. Dengan kata lain, panjang periode berbanding terbalik dengan besarnya energi ombak yang ditangkap konverter, dengan trendline $y=-85,598 x+208,53$ dan tingkat keeratan hubungan $R^{2}=0,8881$. Y adalah energi yang dihasilkan (watt) dan $X$ adalah periode ombak (detik). Formulasi yang dihasilkan dari penelitian ini dapat dijadikan sebagai salah satu rujukan pada penelitian selanjutnya dalam mengatasi variasi periode ombak pada rancang bangun konverter energi ombak rangkaian gear searah sebagai salah satu sumber energi terbarukan.

Kata-kata Kunci: Energi terbarukan, Wave energy converter, Wave period.

\section{Pendahuluan}

Energi merupakan kebutuhan vital untuk mendukung semua aktivitas umat manusia. Pada saat ini, sebagian besar sumber energi yang digunakan berasal dari hasil pembakaran bahan bakar minyak bumi, yang dapat menyebabkan terjadinya masalah lingkungan seperti pencemaran udara dan terjadinya perubahan iklim. Seiring dengan semakin menipisnya sumber minyak bumi, maka sebagian besar negara di dunia mulai sadar akan pentingnya pelestarian lingkungan dan penghematan penggunaan cadangan minyak. Hal ini dilakukan untuk mengurangi tingkat emisi gas $\mathrm{CO}_{2}$ yang dianggap sebagai sumber pencemaran udara. Badan Energi Internasional (EIA) melaporkan bahwa total emisi $\mathrm{CO}_{2}$ secara global pada tahun 2013 yaitu; pembangkit listrik menghasilkan $42 \%$, transportasi $23 \%$, industri $19 \%$, rumah tangga $6 \%$, jasa $3 \%$ dan sektor lainnya $7 \%$. Total $\mathrm{CO}_{2}$ yang dilepaskan ke atmosfer dalam 42 tahun terakhir meningkat sekitar $230 \%$ dari 13.995 .000 ton pada tahun 1971 meningkat menjadi 32,190 juta ton pada tahun 2013 (International Energy Agency, 2015).

Upaya untuk mengatasi emisi $\mathrm{CO}_{2}$ keatmosfir sudah banyak dilakukan melalui pengembangan dan pemanfaatan sumber energi terbarukan non fossil seperti pembangkit listrik tenaga bayu (angin), pembangkit listrik tenaga air, pembangkit lisrik tenaga surya, energi pasang surut air laut, energi arus laut dan energi ombak (Masjono, 2016). Diantara sumber energi alternatif tersebut, energi ombak yang memiliki kandungan energi terbesar yang tersedia selama 24 jam, namun belum banyak di manfaatkan secara maksimal karena biaya per $\mathrm{kWh}$ belum layak secara ekonomis dengan teknologi konverter yang ada saat ini (Assis, et al., 2014).

Penelitian pada bidang pemanfaatan ombak telah menarik perhatian beberapa peneliti antara lain
(Hansen, et al., 2014) memanfaatkan ombak sebagai sumber energi terbarukan dengan memanfaatkan pergerakan naik turun ombak untuk menggerakkan sebuah pompa hidrolik yang dihubungkan dengan turbin untuk memutar generator listrik. Kelly dkk (Kelly, et al., 2013) mengusulkan kombinasi antara pembangkit listrik tenaga ombak terapung dengan pembangkit listrik tenaga angin untuk mengatasi variasi energi listrik yang dihasilkan. Kajian mengenai interaksi konverter ombak dengan sifat non linieritas ombak menggunakan pelampung yang terhubung satu sama lain dilakukan oleh (O'Cathalin, et al., 2008).

Selanjutnya konversi energi potensial pergerakan naik turun pelampung untuk menggerakkan generator magnet permanen secara translasi vertikal telah dilakukan oleh Eriksson (Eriksson, et al., 2005). Dimensi pelampung konverter energi ombak berpengaruh pada efisiensi daya yang dihasilkan oleh konverter energi ombak dan daya optimum diperolah pada saat frekuensi resonansi alamiah pelampung sama dengan frekwensi resonansi gelombag laut (Bozzi, et al., 2013). Konverter energi ombak harus bisa bertahan pada kondisi ombak yang ekstrim.

Untuk mengantisipasi keadaan tersebut digunakan konverter terapung (Pecher, et al., 2012). Untuk memprediksi besaran energi yang dapat ditangkap oleh konverter dilakukan simulasi numerik berdasarkan persamaan model matematika pada domain waktu, baik untuk gelombang reguler maupun gelombang non reguler (Wacher \& Neilsen, 2010). Untuk mengetahui efisiensi daya yang dihasilkan sebuah wave energy converter dapat di prediksi berdasarkan model topologi transmisi hidrostatik menggunakan komponen generik. Model tersebut digunakan untuk mengoptimalkan dimensi komponen untuk mendapatkan efisiensi energi yang dihasilkan (Hansen, et al., 2011). 
Penelitian terdahulu dalam memanfaatkan energi ombak umumnya memanfaatkan daya apung dari ombak tersebut, sehingga energi yang dihasilkan merupakan selisih antara gaya apung dengan gaya gravitasi dari pelampung yang dipergunakan. Hal inilah yang menyebabkan rendahnya efisiensi konverter energi ombak yang ada saat ini. Untuk mengatasi masalah tersebut maka dikembangkan model konverter energi ombak rangkaian gear searah yang hanya memanfatkan gaya gravitasi menggunakan container yang diisi dengan air laut (Masjono, 2016). Kinerja konverter energi ombak rangkaian gear searah dipengaruhi oleh parameter ombak antara lain tinggi ombak, periode ombak dan parameter konverter itu sendiri (Masjono, et al., 2014). Paper ini memaparkan hasil pengujian pengaruh variasi periode ombak terhadap model fisik konverter energi ombak rangkaian gear searah yang dikembangkan di Laboratorium Hidrolika Jurusan Sipil Universitas Hasanuddin bekerja sama dengan Politeknik ATI Makassar.

\section{Energi ombak samudra}

Energi ombak samudra (marine energy) juga kadang-kadang disebut sebagai energi laut, kekuatan laut, atau energi hydrokinetic, mengacu pada energi yang dibawa oleh ombak, pasang surut, perbedaan salinitas, dan perbedaan suhu laut (Callaghan, 2006). Ombak terjadi akibat tiupan angin pada permukaan laut. Kecepatan angin pada permukaan air lebih besar dari kecepatan perambatan gelombang. Hal ini menyebabkan transfer energi dari angin ke ombak. Akibat gesekan angin dengan permukaan laut dalam waktu tertentu menyebabkan tumbuhnya ombak akibat angin tersebut (Vosough, 2011). Secara umum, ombak yang besar memiliki energi yang besar pula, tetapi energi ombak sesungguhnya ditentukan juga oleh kecepatan gelombang, panjang gelombang dan berat jenis air laut (Thomas, 2014).

Energi ombak yang paling besar terdapat di permukaan yang akan semakin kecil pada kedalaman. Energi rata-rata pada bidang vertikal pada lebar tertentu dan paralel terhadap puncak ombak disebut wave energy flux (Thomas, 2014). Berdasarkan linear theory, tidak ada pergerakan patikel air laut, namun yang terjadi adalah adanya perpindahan energi (transport of energy). Terdapat dua jenis energi yang ada pada ombak yaitu, energi kinetik akibat gerakan fluida dan yang kedua adalah energi potensial akibat variasi ketinggian air laut. Resonansi antara kedua jenis energi tersebut menyebabkan ombak bergerak. Secara matematis, energi yang terkandung dalam ombak dapat diuraikan sebagai berikut (Falnes, 2004):
Energi potensial ombak,

$E_{p}=\frac{\rho g}{4} a^{2}$

Energi kinetik,

$E_{k}=\frac{\rho g}{4} a^{2}$

Total energi adalah gabungan antara energi kinetik dan energi potensial,

$E_{T}=E_{p}+E_{k}=\frac{\rho g}{4} a^{2}+\frac{\rho g}{4} a^{2}=\frac{\rho g}{2} a^{2} .$.

dimana:

$\mathrm{E}_{\mathrm{T}}=$ total energi ombak

$\rho=$ berat jenis air laut

$\mathrm{g}=$ percepatan gravitasi

$a=$ amplitude ombak

Aliran energi rata-rata adalah laju perubahan energi yang merambat per satuan panjang puncak ombak melalui bidang vertikal dan tegak lurus terhadap arah perambatan/propagasi. Besaran energi tersebut diperoleh dari hasil perkalian antara total energi $\boldsymbol{E}_{\boldsymbol{T}}$ dengan kecepatan (group velocity) $\boldsymbol{C}_{\boldsymbol{g}}$ (Assis, et al., 2014) sehingga diperoleh Persamaan 4:

$P=E_{T} \times C_{g}$

Group velocity untuk ombak pada kedalaman lebih besar dari 1/4 kali panjang gelombang atau $d>$ L/4, diperoleh hubungan sebagai berikut:

$C_{g}=\frac{g}{2 \omega}=\frac{g}{4 \pi f}=\frac{g T}{4 \pi}$

$P=\frac{1}{2} \rho g a^{2} \cdot \frac{g T}{4 \pi}$

Dengan subtitusi jarak antara crest dan trough dimana amplitude ombak linier a $=\mathrm{H} / 2$ maka Persamaan 6 menjadi:

$P=\frac{1}{32 \pi} \rho g^{2} H^{2} T$

dimana:

$\mathrm{P}$ = daya rata-rata untuk gelombang linier

$\rho=$ berat jenis air laut $\left(1025 \mathrm{~kg} / \mathrm{m}^{3}\right)$

$\mathrm{H}=$ tinggi ombak

$\mathrm{T}=$ periode ombak

Keadaan ombak di laut yang sesungguhnya dapat dimodelkan sebagai proses yang acak yang merupakan hasil superposisi dari beberapa ombak linier dengan parameter dan arah yang berbeda satu sama lain. Untuk itu parameter ombak seperti periode, tinggi, dan arah harus di kelola dengan metode statistik. Parameter statistik yang dipergunakan adalah tinggi ombak yang signifikan (significant wave height) $\boldsymbol{H s}$ dan periode ombak rata-rata. Energi yang terkandung di dalam ombak laut dinyatakan dengan Persamaan 8 (Assis, et al., 2014). 
$P=\frac{\rho g^{2}}{64 \pi} H_{s}^{2} T \approx\left(0.5 \frac{\mathrm{kW}}{\mathrm{m}^{3} \cdot s}\right) H_{s}^{2} T$

dimana:

$\mathrm{P}=$ wave power density per unit horizontal area $(\mathrm{W} / \mathrm{m})$

Hs = significant wave height

$\mathrm{T}=$ periode rata-rata

$\rho=$ water density

$\mathrm{g}=$ acceleration by gravity

\section{Pengujian Model Fisik}

Model fisik yang dikembangkan pada Laboratorium Hidrolika Jurusan sipil Universitas Hasanuddin merupakan kelanjutan dari penelitian pengembangan model matematis sebelumnya (Masjono, 2016). Ilustrasi model matematis dapat dilihat pada Gambar 1. Konstruksi model fisik terdiri atas gear searah, counter weight, container plastik, rantai penghubung, gear box dan plywheel. Sebelum pengujian variasi periode ombak dilakukan, perlu dipastikan bahwa semua counter weight dan gravity weight yang dipergunakan memiliki massa yang sama yang diukur menggunakan timbangan digital.

\section{Spesifikasi model fisik}

Uji model fisik dilaksanakan pada simulator ombak (flume) di Laboratorium Hidrolika Jurusan Teknik Sipil Universitas Hasanuddin. Spesifikasi model fisik yang digunakan pada uji coba ini adalah sebagai berikut:
a. Panjang $=435 \mathrm{~cm}$
b. Lebar $=26 \mathrm{~cm}$
c. Tinggi $=56 \mathrm{~cm}$

Dimensi container plastic yang digunakan

a. Panjang $=28,5 \mathrm{~cm}$

b. Lebar $=23 \mathrm{~cm}$
c. Tinggi $=10 \mathrm{~cm}$
d. Massa kosong = 494 gram
e. Massa jika terisi penuh air $=5024$ gram
f. Massa counter weight $=328$ gram

\section{Alat Ukur}

Alat ukur utama yang dipergunakan pada pengujian model fisik ini terdiri atas:

1. Torsi meter yang berfungsi untuk mengukur torsi pada poros konverter dan poros plywheel.

2. Wave monitor sebagai sensor yang dapat mengukur parameter ombak.

3. Osiloskop digital untuk mengukur periode ombak berdasarkan hasil pembacaan wave monitor.

4. Tachometer digital utuk mengukur kecepatan putaran poros konverter.

\section{Parameter yang diukur}

Parameter yang diukur diadalam experiment model fisik konverter energi ombak rangkaian gear searah terdiri atas tinggi ombak sebelum konverter untuk mengetahui berapa input energi yang masuk ke konverter, tinggi ombak setelah melewati konverter untuk mengetahu berapa energi yang terserap. Energi yang dihasilkan konverter merupakan hasil perkalian antara kecepatan putaran plywheel dengan torsi yang dihasilkan.

Pada pecobaan ini pada saat periode ombak divariasikan berimbas pula pada panjang gelombang $\lambda$. Tinggi ombak bervariasi dari 5 s/d 9 $\mathrm{cm}$, massa container (gravity weight) dan counter weight masing-masing seberat $5,024 \mathrm{~kg}$ dan $0,328 \mathrm{~kg}$. Periode ombak yang diukur dengan menggunakan osiloskop digital bervariasi antara $1,2 \mathrm{~s} / \mathrm{d} 2,25$ detik. jarak antara gear $\left(\mathrm{G}_{\mathrm{s}}\right)=40 \mathrm{~cm}$ dan kedalaman air $25 \mathrm{~cm}$.

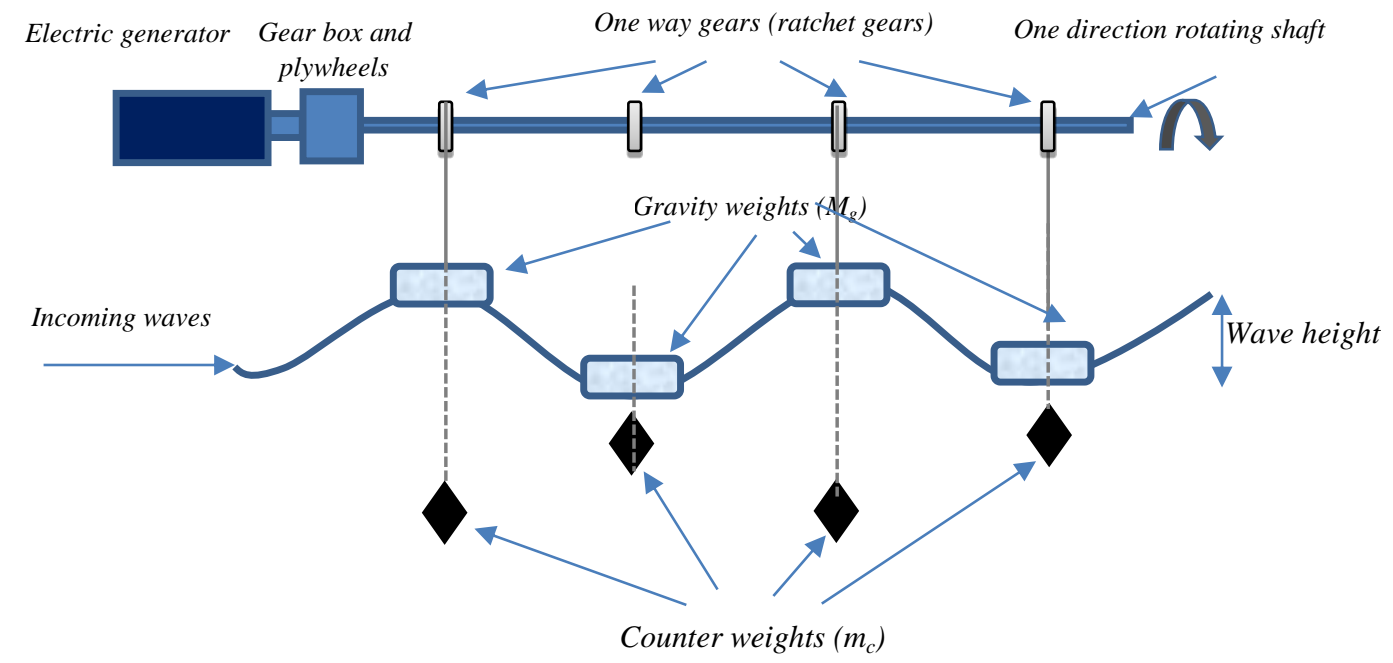

Gambar 1. Ilustrasi model konverter energi ombak rangkaian gear searah (Masjono, 2016) 


\section{Hasil dan Pembahasan}

Energi ombak yang ditangkap oleh konverter adalah hasil kali antara data hasil pengukuran kecepatan putaran (RPM) poros plywheel dengan torsi (Nm) yang terukur pada poros yang sama. Kecepatan putaran diukur menggunakan Tachometer digital dan torsi diukur menggunakan Newton Meter Scale.

Hasil pengukuran kecepatan putaran (RPM) dan Torsi disajikan pada Tabel 1. Setelah diolah menggunakan statistic tool yang terdapat pada software computer microsoft excel diperoleh hubungan dalam bentuk grafik pada Gambar 2 . Berdasarkan pada gambar tersebut, nampak bawa periode ombak berbanding terbalik dengan energi yang dihasilkan konverter. Semakin pendek periode (T), maka semakin besar energi yang dihasilkan. Demikian pula sebaliknya, semakin panjang periode semakin kecil energi yang dihasilkan. Pola hubungan tersebut dalam bentuk trendline berdasarkan pengolahan data dengan tools statistic Microsoft exell diperoleh diperoleh rumus empiris;

$y=-85,598 x+208,53$

dimana:

$\mathrm{y}=$ energi yang dihasilkan (watt)

$\mathrm{x}=$ periode ombak (detik)

dengan tingkat keberterimaan $\mathrm{R}^{2}=0,8881$ atau $88,81 \%$.

Persamaan 9 merupakan persamaan enpiris yang mengambarkan hubungan antara perubahan periode ombak terhadap energi yang dihasilkan oleh konverter energi ombak rangkaian gear searah. Namun hasil percobaan ini hanya berlaku untuk ombak linier yang dibangkitkan menggunkan simulator ombak atau flume di laboratorium. Untuk kondisi real di laut diperlukan uji lanjutan mengunakan simulator ombak non linier atau uji langsung di laut.

Tabel 1. Hasil pengukuran variasi periode ombak

\begin{tabular}{|c|c|c|c|c|c|}
\hline $\begin{array}{l}\text { Tinggi ombak } \\
\text { (cm) }\end{array}$ & $\begin{array}{c}\text { Periode ombak } \\
\text { (detik) }\end{array}$ & $\begin{array}{c}\text { Panjang gelombang K } \\
(\mathrm{cm})\end{array}$ & $\begin{array}{l}\text { Kecepatan putaran } \\
\text { (rpm) }\end{array}$ & $\begin{array}{l}\text { Torsi }(\tau) \\
(\mathbf{n m})\end{array}$ & $\begin{array}{l}\text { Daya } \\
\text { (watt) }\end{array}$ \\
\hline 5 & 2,20 & 330 & 93,4 & 3,7 & 36,19 \\
\hline 5 & 2,00 & 290 & 55,6 & 3,7 & 21,54 \\
\hline 5,5 & 1,85 & 260 & 109,9 & 4,5 & 51,79 \\
\hline 5 & 1,70 & 240 & 106,6 & 5,0 & 55,81 \\
\hline 5 & 1,60 & 220 & 126,3 & 5,5 & 72,74 \\
\hline 6 & 1,50 & 210 & 137,5 & 5,5 & 79,19 \\
\hline 7 & 1,40 & 200 & 154,0 & 5,5 & 88,69 \\
\hline 7 & 1,30 & 190 & 159,3 & 5,0 & 83,40 \\
\hline 8,5 & 1,25 & 175 & 190,9 & 5,5 & 109,94 \\
\hline 9 & 1,20 & 160 & 202,2 & 5,5 & 116,45 \\
\hline
\end{tabular}

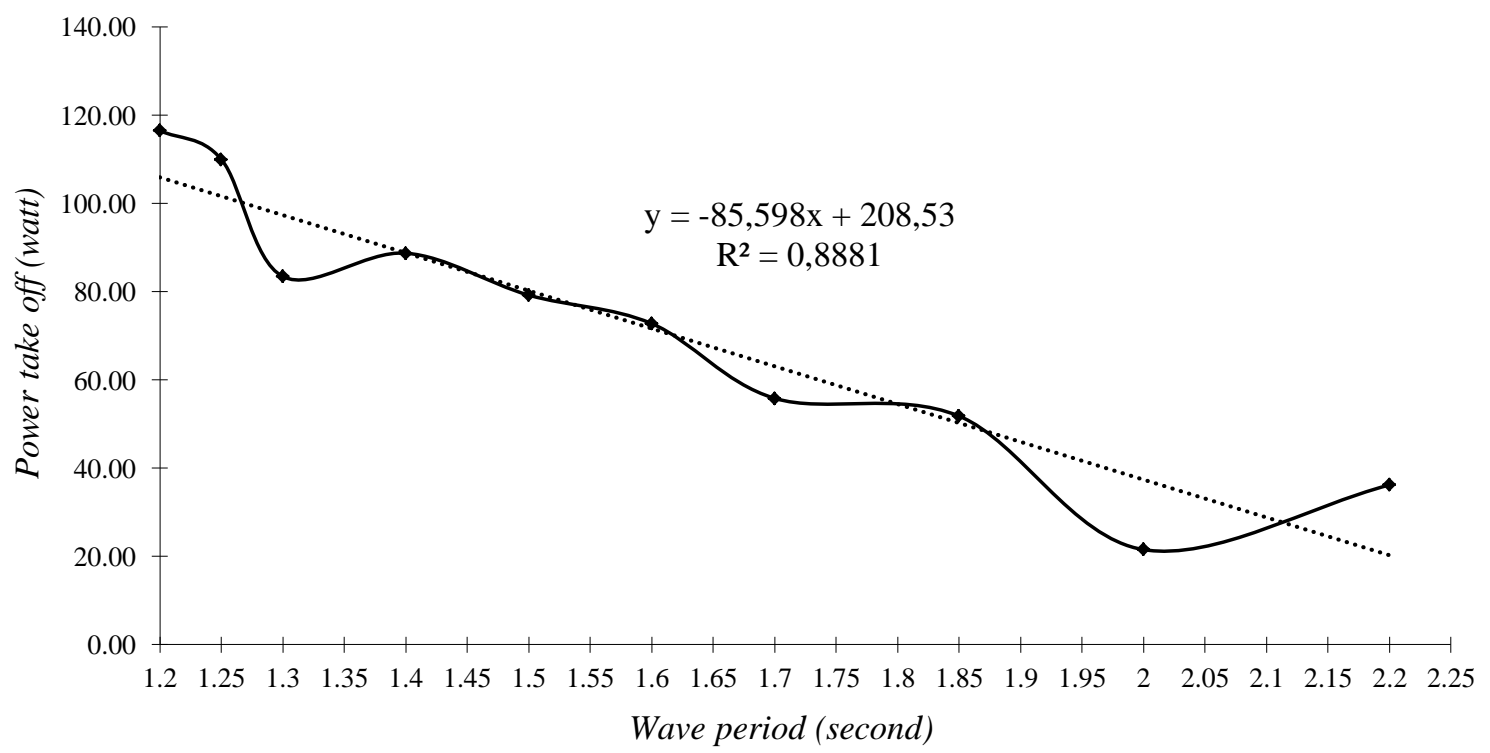

Gambar 2. Grafik hubungan antara periode ombak dengan energi yang dihasilkan konverter. 


\section{Kesimpulan}

Berdasarkan hasil pengukuran uji coba model fisik di Laboratorium Hidrolika Universitas Hasanuddin, dapat disimpulkan bahwa periode ombak berpengaruh terhadap kinerja konverter energi ombak rangkaian gear searah. Besarnya energi yang ditangkap oleh konverter berbanding terbalik dengan panjang periode ombak. Semakin panjang periode ombak semakin kecil energi yang dihasilkan. Hasil yang diperoleh dari penelitian ini hanya berlaku untuk ombak reguler. Untuk ombak non reguler diperlukan penelitian lebih lanjut sebelum konverter ini di implementasikan secara langsung di laut.

\section{Ucapan Terima Kasih}

Ucapan terima kasih disampaiakn kepada Kementrian Perindustrian Republik Indonesia dan Politeknik ATI Makassar atas dukungan finansial yang diberikan sehingga penelitian ini dapat diselesaikan dengan baik.

\section{Daftar Pustaka}

Assis, L. E., Beluco, A., \& Almeida, L. E. B. d., 2014. On The Wave Energy Potential Along the Sothern Coast of Brazil, International Journal of Energy and Environment (IJEE), 5 (1), pp. 59-66.

Bozzi, S., et al., 2013. Modeling of a Point Absorber for Energy Conversion in Italian Seas, Energies, 6 (6), pp. 3033-3051.

Callaghan, J., 2006. Future Marine Energy, The Carbon Trust, London, UK.

Eriksson, M., Isberg, J., \& Leijon, M., 2005. Hydrodynamic Modelling of a Direct Drive Wave Energy Converter, International Journal of Engineering Science, 43 (17-18), p. 1377-1387.

Falnes, J., 2004. Wave Transport of Energy and Momentum. Dalam: Ocean Waves and Oscillating Systems, Cambridge University Press, pp. 75-77, Cambridge.

Hansen, R., H., Andersen, T., O., \& Pedersen, H., C., 2011. Model Based Design of Efficient Power Take-Off Systems for Wave Energy Converters. Tampere, Finland, S.N.
Hansen, R. H., Kramer, M. M. \& Vidal, E., 2014. Discrete Displacement Hydraulic Power Take-Off System for the Wavestar Wave Energy Converter, Energies, pp. 400-4044.

International Energy Agency, 2015. CO2 Emissions from Fuel Combustion Highlights, International Energy Agency, Paris, France.

Kelly, T., Dooley, T., Campbell, J., \& Ringwood, J., 2013. Comparison of the Experimental and Numerical Results of Modelling a 32-oscillating Water Column (OWC), V-shaped Floating Wave Energy Converter, Energies, 6 (8), pp. 4045-4077.

Masjono, 2016. Modelling of One Way Gears Wave Energy Converter for Irregular Ocean Waves to Generate Electricity, Jurnal Teknologi, 78 (5-7), pp. 37-41.

Masjono, Manjang, S., Zainuddin, Z. \& Thaha, A., 2014. Modelling and Numerical Simulation of Multiple One Way Gearswave Energy Converter to Generate Electricity, Kuta, Bali, Smart Green Technology in Electrical and Information Systems (ICSGTEIS), 2014 International Conference on.

O’Cathalin, M., Leira, B. J., Ringwood, J. V. \& Gilloteaux, J.-C., 2008. A Modelling Methodology for Multi-Body Systems With Application to Wave-Energy Devices, Ocean Engineering, 35 (13), p. 1381- 1387.

Pecher, A., Kofoed, J., P., \& Larsen, T., 2012. Design Specifications for the Hanstholm WEPTOS Wave Energy Converter, Energies, 5 (4), pp. 10011017.

Thomas, G., 2014. Wave Power: Theory Behind Ocean Waves. [Online] Available at:

http://www.azocleantech.com/article.aspx?ArticleI $\mathrm{D}=227[$ Diakses 7 July 2016].

Vosough, A., 2011. Wave Energy. International Journal of Multidisciplinary Sciences and Engineering, 2 (7), pp. 60- 63.

Wacher, A. \& Neilsen, K., 2010. Mathematical and Numerical Modeling of the Aqua BuOY Wave Energy Converter, Mathematics-in-Industry Case Studies Journal, Volume 2, pp. 16-33. 